\title{
Effect of the Viscous Exudate of Mekabu (Sporophyll of Undaria pinnatifida) on Glucose Absorption in Rats
}

\author{
Natsumi YAmanaKA, ${ }^{1}$ Noriko OGAWA, ${ }^{1}$ Toru TAKAHASHI, ${ }^{2}$ Yuko MAKI ${ }^{3}$ and Takashi SAKATA ${ }^{4}$ \\ ${ }^{1}$ Department of Nutrition and Food Science, Gifu Women's University, 80 Taromaru, Gifu 501-2592, Japan \\ ${ }^{2}$ Department of Anatomy, Gifu University School of Medicine, 40 Tsukasa, Gifu 500-8076, Japan \\ ${ }^{3}$ School of Science and Engineering, ${ }^{4}$ Department of Basic Sciences, Ishinomaki Senshu University, Minamisakai Shinmito, Ishinomaki 986-8580, \\ Japan
}

Received April 18, 2000; Accepted September 22, 2000

The absorption of glucose in rats was investigated to elucidate the effect of ingesting the viscous exudate of $m e$ $k a b u$ on digestive absorption. A solution containing $10 \%$ dried viscous exudate of mekabu and $10 \%$ glucose was administered orally to rats. Changes in blood sugar levels were then measured as well as retention time of the contents in the stomach and small intestine using rats which had undergone surgery to connect the end of the ileum with the distal colon. It was found that the maximum blood sugar levels tended to be lower in the rats which had received the feed with viscous exudate than in those in a control group which had received the solution containing glucose only; this suggested that the ingestion of mekabu viscous exudate together with glucose suppressed the maximum blood sugar level. The retention time in the stomach and small intestine was longer in the group administered feed containing viscous exudate than in the control group. Movement of the contents from the stomach to the small intestine was delayed, which is presumed to be the cause of the suppressed rise in blood sugar level. The viscosity of viscous exudate samples prepared at $10^{\circ} \mathrm{C}$ and $80^{\circ} \mathrm{C}$ differed, and we also investigated whether or not this difference affected glucose absorption. Rats given the feed containing the viscous exudate prepared at $80^{\circ} \mathrm{C}$, which had a higher viscosity, had lower maximum blood sugar levels than those ingesting the feed containing $10^{\circ} \mathrm{C}$ exudate. The retention time of the digestive tract contents was also longer, and the fecal weight and sugar amount in feces tended to be greater.

Keywords: mekabu, viscous exudate, viscosity, glucose, blood sugar

Mekabu is the sporophyll of wakame (Undaria pinnatifida), which is characterized by its abundant stickiness. In Japan meka$b u$ is used for its glutinous properties in the preparation of soups and Japanese-style vegetable dishes. The stickiness of mekabu derives from the elution of indigestible polysaccharides, such as alginic acid, which are contained intracellularly in brown algae (Phaeophyceae) (Yamanaka \& Ogawa, 1998).

Because this viscosity plays a large part in the physiological effect of water-soluble dietary fiber (Takeda \& Kiriyama, 1995; Takehisa, 1997), the stickiness of mekabu has been a focus of attention, and its physiological effects studied. The sticky exudate that is obtained when mekabu is put in water and stirred (mekabu viscous exudate) was freeze-dried, added to feed at 3\%, and fed to rats, resulting in a significant drop in food efficiency and an increase in fecal weight (Yamanaka et al., 1998); this suggested the possibility that the ingestion of mekabu viscous exudate interferes with the digestive absorption of other nutrients. To elucidate this possibility, the present study examined the effect on glucose absorption of mekabu viscous exudate added to feed and ingested orally by rats.

The obstruction of digestive absorption of other nutrients that is brought about by mekabu viscous exudate is thought to be due to certain components in the exudate. This hypothesis was investigated by evaluating the effect on digestive absorption when sodium alginate, the main component of mekabu viscous exu-

E-mail: natsumi@gijodai.ac.jp date, was added to feed. The results showed that the weight of cecum tissue in the rats increased with the ingestion of either the exudate or sodium alginate extracted from mekabu, whereas the weight of stomach tissue increased in rats which ingested the mekabu exudate, but not in those which ingested sodium alginate. The food efficiency of the former group of rats also decreased, but not that of rats which ingested alginic acid (Yamanaka et al., 1996). Since the effects on digestive absorption of mekabu viscous exudate and its main component sodium alginate were not exactly the same, it is presumed that some other component of the viscous exudate is responsible for the physiological effect. Moreover, considering the contribution of the physical properties of feed on the digestive absorption of nutrients, a powdered feed was not used as in earlier studies. Rather, freeze-dried mekabu viscous exudate with different viscosities from its preparation at $10^{\circ} \mathrm{C}$ and $80^{\circ} \mathrm{C}$ (Yamanaka \& Ogawa, 2000) was dissolved in water. Using this feed with differing degrees of stickiness, the effects of different viscosities on glucose absorption were also investigated.

\section{Methods}

Mekabu viscous exudate was fed to rats together with glucose, and the changes in blood sugar were measured. The retention time of digestive tract contents was also examined by the amount of non-absorptive Co-EDTA, which had been added to the feed as a marker, excreted in feces (Sakaguchi \& Nabata, 1992). Retention time in the stomach and small intestine is thought to be 
the main factor in glucose absorption; however, between the mouth and the anus the longest retention time is in the large intestine. Therefore, in the present study, the end of the ileum was surgically connected to the distal colon in order to measure the retention time in the stomach and small intestine. The weight of the feces excreted after the rats had been administered the feed, and the sugar amount in the feces, were also measured.

Preparation of mekabu viscous exudate Sixty grams of dried mekabu produced in Korea were cut finely into pieces $5 \times 15 \mathrm{~mm}$ and added to $300 \mathrm{~g}$ of water at either $80^{\circ} \mathrm{C}$ or $10^{\circ} \mathrm{C}$. The samples were left immersed in the constant temperature baths at either temperature for $5 \mathrm{~min}$. After stirring for $5 \mathrm{~min}$ at $150 \mathrm{rpm}$, this was filtered through a double-layer of gauze, and the filtrate taken as the mekabu viscous exudate. This exudate was then freeze-dried and pulverized for use in the experiments.

Conditions for experimental animals and feed Six-weekold male Wistar rats were used. They were raised on ordinary solid food (Oriental Yeast Co., Ltd, MF) and water was given ad libitum, in individual stainless steel cages with a room temperature of $24^{\circ} \mathrm{C}$, humidity $60 \%$, and a cycle of $12 \mathrm{~h}$ darkness (6:0018:00)/12 h light (18:00-6:00).

Surgery We performed ceco-colonic bypass surgery. We anesthetized rats with sodium pentobarbitone $(25 \mathrm{mg} / \mathrm{kg}$ body weight, intraperitoneally; Nembutal (R), Dainippon Seiyaku, Osaka) and conducted a midline laparotomy. The ileum was cut at approximately $3 \mathrm{~cm}$ orad to the ileo-cecal junction. The aboral cut end was closed to form a bling stump with sutures after folding that end (ca. $5 \mathrm{~mm}$ long) into the lumen. Then, we made a longitudinal opening of approximately $7 \mathrm{~mm}$ at the antimesenteric side of the distal colon approximately $3 \mathrm{~cm}$ orad to its aboral end in the abdominal cavity. The oral cut end of the ileum was inserted to the lumen of the distal colon through this opening to form end-to-side ileocolonic anastomosis. After rinsing the abdominal cavity with physiological saline solution we closed it by suturing the peritoneum and muscle layers with a single continuous suture and the skin with another continuous suture.

Experimental feed Composition of the experimental feed is shown in Table 1. Ten grams of mekabu viscous exudate and $10 \mathrm{~g}$ of glucose (Wako Pure Chemical Industries, Ltd., Osaka) were included in $100 \mathrm{~g}$ of feed. The rats were given $1 \mathrm{~g}$ of experimental feed per $100 \mathrm{~g}$ body weight, making the amounts of me$k a b u$ viscous exudate and glucose each $100 \mathrm{mg} / 100 \mathrm{~g}$ body weight. One hundred milligrams of dried exudate was the equivalent of the viscous exudate eluted from approximately $0.30 \mathrm{~g}$ of dried mekabu at $80^{\circ} \mathrm{C}$, and from approximately $0.39 \mathrm{~g}$ at $10^{\circ} \mathrm{C}$.

The apparent viscosity of feed including dried viscous exudate was measured at $100 \mathrm{rpm}$ and $37^{\circ} \mathrm{C}$ using a TV-20 type viscome-

Table 1. Composition of the experimental feed.

\begin{tabular}{lccc}
\hline & $\begin{array}{c}80^{\circ} \mathrm{C} \text { viscous } \\
\text { exudate feed } \\
(\%)\end{array}$ & $\begin{array}{c}10^{\circ} \mathrm{C} \text { viscous } \\
\text { exudate feed } \\
(\%)\end{array}$ & $\begin{array}{c}\text { Control } \\
(\%)\end{array}$ \\
\hline $\begin{array}{l}\text { Dried viscous exudate of } \\
\text { mekabu prepared at } 80^{\circ} \mathrm{C}\end{array}$ & 10 & - & - \\
Dried viscous exudate of & - & 10 & - \\
mekabu prepared at $10^{\circ} \mathrm{C}$ & & & 10 \\
Glucose & 10 & 10 & 20 \\
Co-EDTA & 20 & 20 & 70 \\
Water & 60 & 60 & \\
\hline
\end{tabular}

ter (Tokimec, Inc., Tokyo). The viscosity of feed containing dried viscous exudate of mekabu prepared at $80^{\circ} \mathrm{C}\left(80^{\circ} \mathrm{C}\right.$ viscous exudate feed) was $106.4 \mathrm{cP}$, and that of feed containing dried viscous exudate of mekabu prepared at $10^{\circ} \mathrm{C}\left(10^{\circ} \mathrm{C}\right.$ viscous exudate feed $)$ was $28.5 \mathrm{cP}$, a difference of about 3.7 fold in the viscosities of the feed used.

Rats given the control feed containing only glucose without any experimental specimens were taken as a control group. Twenty percent Co-EDTA (Dojindo Laboratories, Kumamoto) was added to all the feeds.

Oral administration of experimental feed Using rats 6-8 days after surgery, each type of experimental feed $(1 \mathrm{~g} / 100 \mathrm{~g}$ body weight) was administered perorally through a tube into the stomach of those that had been fasted at least $5 \mathrm{~h}$ following start of the dark cycle.

\section{Measurements and methods}

Blood sugar Immediately before administration of the experimental feed $(0 \mathrm{~h})$, and $0.5,1,2$, and $4 \mathrm{~h}$ after administration, blood was collected through a heparin-treated capillary tube in the tail vein, and immediately centrifuged to obtain plasma. Blood sugar levels were measured using a glucose measuring kit (Wako Pure Chemical, Glucose C II-Test Wako).

Fecal weight Feces from the individual cages were gathered $1,2,4,7,10$, and $20 \mathrm{~h}$ after administration of the experimental feed, and the weight was measured.

Retention time of digestive tract contents Approximately 0.3 $\mathrm{g}$ of the feces gathered each time was diluted 2-fold in an equal amount of water, after which $1 \mathrm{ml}$ diethyl ether was added and the mixture was shaken for $60 \mathrm{~min}$ (300 strokes/min) to extract the fat-soluble dye. After centrifuging $(10,000 \mathrm{~g} \times 20 \mathrm{~min})$, the ether layer was removed and the light absorbance at the maximum absorption wavelength $(466 \mathrm{~nm})$ of the Co-EDTA aqueous solution was measured for the remaining aqueous layer. The amount of Co-EDTA in the aqueous layer was determined from the working curve plotted using $0.5-1.0 \mathrm{~g} / 100 \mathrm{ml}$ of Co-EDTA aqueous solution, and taken as the Co-EDTA amount in feces. The amount of Co-EDTA in total collected feces was calculated, and a mean retention time (MRT) was figured using the formula of Thielemans et al. (1978): MRT $=\Sigma t i c i \Delta t i / \Sigma c i \Delta t i$, where $c i$ is the marker concentration at the time after administration $t i$, and $\Delta t i$ is the $i$ th sampling interval.

Sugar in feces Using the aqueous layer prepared when measuring the Co-EDTA in feces, the reducing sugar was quantified as a standard glucose sample by the Somogyi-Nelson method to determine the amount of sugar excreted in feces.

Statistical analysis The results for each measured item are expressed as the mean \pm standard error of the measurements for 4 animals in one group. The differences in mean values between the groups were tested using Duncan's multiple range test.

\section{Results}

Changes in blood sugar level Taking the blood sugar level immediately before the administration of the experimental feed as 0 , the changes in this level at $0.5,1,2$, and $4 \mathrm{~h}$ after the administration are shown in Fig. 1. In all 3 groups, the maximum blood sugar levels were seen at $1 \mathrm{~h}$ after administration of the feed. This was highest in the control group at $52.8 \mathrm{mg} / 100 \mathrm{ml}$, followed by the $10^{\circ} \mathrm{C}$ viscous exudate feed group at $45.8 \mathrm{mg} / 100$ $\mathrm{ml}$ and the $80^{\circ} \mathrm{C}$ viscous exudate feed group at $40.8 \mathrm{mg} / 100 \mathrm{ml}$. 


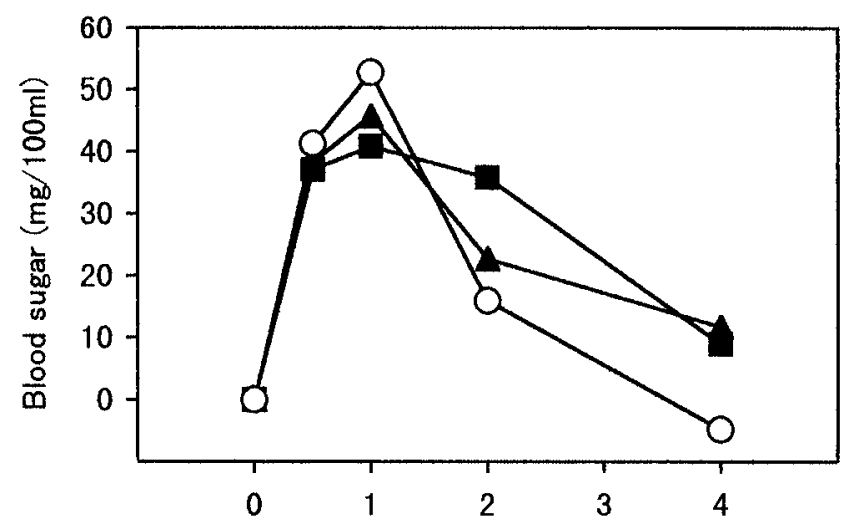

Fig. 1. Influence of mekabu viscous exudate on the blood sugar level in rats $\mathbf{m}, 80^{\circ} \mathrm{C}$ viscous exudate feed group; $\mathbf{\Lambda}, 10^{\circ} \mathrm{C}$ viscous exudate feed group; $\bigcirc$, control group.

While there was no significant difference among any of the groups, the maximum blood sugar value tended to be lower with more highly viscous feed. The blood sugar level in the control group dropped rapidly at 2 and $4 \mathrm{~h}$ after administration of feed, whereas in the $80^{\circ} \mathrm{C}$ viscous exudate feed group the decline was more gradual. Total glucose absorption calculated from blood sugar values was $98.3 \mathrm{mg} / 100 \mathrm{ml} / 4 \mathrm{~h}$ in the control group, 102.3 in the $10^{\circ} \mathrm{C}$ viscous exudate feed group, and 113.0 in the $80^{\circ} \mathrm{C}$ viscous exudate feed group. No significant difference was found among any of the groups.

Fecal weight The total weight of feces excreted up to $20 \mathrm{~h}$ after administration of feed is shown in Table 2. This amount was greater in the $80^{\circ} \mathrm{C}$ viscous exudate feed group at $5.03 \mathrm{~g}$, than in the $10^{\circ} \mathrm{C}$ viscous exudate feed and control groups at $2.77 \mathrm{~g}$ and $2.44 \mathrm{~g}$, respectively.

Retention time of digestive tract contents Retention time of the digestive tract contents of rats ingesting each type of feed are shown in Table 2. That of the $80^{\circ} \mathrm{C}$ viscous exudate feed group was longest at $16.77 \mathrm{~h}$, followed by the $10^{\circ} \mathrm{C}$ viscous exudate feed group at $10.61 \mathrm{~h}$ and the control group at $7.01 \mathrm{~h}$. The difference between the $80^{\circ} \mathrm{C}$ exudate feed group and the control group was statistically significant $(p<0.05)$.

Sugar in feces The total amount of sugar in feces excreted up to $20 \mathrm{~h}$ after administration of feed is shown in Table 2 . It was $3.17 \mathrm{mg}$ in the $80^{\circ} \mathrm{C}$ exudate feed group, higher than the $2.06 \mathrm{mg}$ in the $10^{\circ} \mathrm{C}$ exudate feed group and the $2.23 \mathrm{mg}$ in the control group, although none of the differences was significant.

\section{Discussion}

The blood sugar levels $1 \mathrm{~h}$ after feed administration tended to be lower in the viscous exudate feed groups than in the control group, indicating the possibility that ingesting mekabu viscous exudate together with glucose suppresses the maximum blood sugar level. Two possible mechanisms acting to suppress the blood sugar rise caused by the temporary ingestion of dietary fiber are (1) that dietary fiber causes a delay in the movement of carbohydrates from the stomach to the small intestine, and (2) that it interferes with or delays the digestive absorption of carbohydrates in the small intestine (Oku, 1995). In the present study as well, the retention time in the stomach and small intestine was longer in the viscous exudate feed groups than in the control, from which it can be reasoned that ingestion of the exudate is the primary cause of the longer retention time of contents in stomach and the suppression of rapid rises in blood sugar.

The final glucose absorption was estimated from the changes in blood sugar and the amount of sugar in feces. No influence due to the ingestion of viscous exudate was seen, so it did not appear that the absorption of glucose in the small intestine had been blocked. However, there was a great effect of the speed of agitation and diffusion of nutrients in the digestive tract on digestion and absorption, and this agitation and dispersion was inhibited by digestive tract contents of higher viscosity. Jenkins et al. (1978) and Flourie et al. (1984) pointed out that the higher the viscosity of dietary fiber, the greater the inhibitory effect on glucose absorption in the intestines, which is thought to be caused by an increase in the thickness of the unstirred water layer covering the small intestine mucosa (Flourie et al., 1984). In the present study as well, rats that had ingested the higher viscosity $80^{\circ} \mathrm{C}$ viscous exudate feed had lower maximum blood sugar levels than those that had ingested the $10^{\circ} \mathrm{C}$ exudate feed. It is thus very probable that the increased viscosity of the digestive tract contents caused by the ingestion of mekabu viscous exudate results in the delayed absorption of glucose in the small intestine. However, since there was no difference in the total amount of absorbed glucose, it does not appear that this obstruction of glucose absorption reaches the point of complete blockage. Future studies examining the viscosity of digestive tract contents together with measurements of retention time in both the stomach and small intestine will shed further light on the mechanism by which mekabu viscous exudate inhibits the rise in blood sugar levels.

The viscous exudate of mekabu was partially hydrolyzed by pancreatin, and the amount of reducing sugar increased upon in vitro digestion (Yamanaka \& Ogawa, 1999). Therefore, it is also possible in the present study that the metabolites formed from the viscous exudate influenced the blood sugar levels and the amount of sugar in feces. The total amount of sugar in feces in the $80^{\circ} \mathrm{C}$ viscous exudate feed group was considerably higher than that in the other two groups. It is suggested that more metabolite was excreted in feces because the viscous exudate prepared at $80^{\circ} \mathrm{C}$, which had a higher viscosity, was metabolized more slowly than the $10^{\circ} \mathrm{C}$ viscous exudate.

Table 2. Influence of mekabu viscous exudate on fecal weight, retention time of digestive tract contents and sugar in feces.

\begin{tabular}{|c|c|c|c|}
\hline & $80^{\circ} \mathrm{C}$ viscous exudate feed group & $10^{\circ} \mathrm{C}$ viscous exudate feed group & Control group \\
\hline Fecal weight $(\mathrm{g} / 20 \mathrm{~h})$ & $5.03 \pm 2.40$ & $2.77 \pm 0.59$ & $2.44 \pm 1.10$ \\
\hline Retention time $(\mathrm{h})$ & $16.77 \pm 1.45^{a)}$ & $10.61 \pm 2.80^{a, b)}$ & $7.01 \pm 0.07^{b)}$ \\
\hline Sugar in feces $(\mathrm{mg} / 20 \mathrm{~h})$ & $3.17 \pm 1.92$ & $2.06 \pm 0.58$ & $2.23 \pm 1.59$ \\
\hline
\end{tabular}

Values are means \pm SE of four rats.

${ }^{a, b)}$ Values in the same row not sharing a common superscript differ significantly using Duncan's multiple range test $(p<0.05)$. 
Using glucomannan of differing viscosities, Doi et al. (1982) looked at the relationship between the viscosity of dietary fiber and the inhibitory action on rises in blood sugar levels. They found that high viscosity glucomannan strongly inhibited increases in blood sugar. The present study also indicates a possible inhibitory effect on elevation of blood sugar by mekabu viscous exudate prepared under different conditions and having different viscosities. The viscous exudate of mekabu immersed and stirred at $80^{\circ} \mathrm{C}$ not only elutes a greater amount of alginic acid than that prepared at $10^{\circ} \mathrm{C}$, it also has a different distribution of sugar molecular weight, and it is known that a sugar with a molecular weight of about 100,000 is the cause of the difference in viscosity (Maki et al., 2001). Thus, the conditions under which mekabu is prepared affect the physicochemical properties of the viscous exudate, which are closely related to its physiological effect. Under the present experimental conditions, no significant differences were seen in the measured values among any of the groups; however, we plan further investigations under conditions such as increased feed volume of viscous exudate and long-term administration periods in order to develop a clearer understanding of the effects of mekabu viscous exudate on digestive absorption, and the relationship between this and the conditions of preparation.

Acknowledgments This study was supported by a grant-in-aid from the Urakami Foundation.

\section{References}

Doi, K., Matsuura, M., Kawara, A., Baba, S. and Nishikawa, K. (1982). Treatment of diabetics with dietary fibers (IV). The effect of high viscosity of dietary fibers on the postprandial blood glucose. Tounyoubyou, 25, 197-203 (in Japanese).

Flourie, B., Vidon, N., Florent, C.H. and Bernier, J.J. (1984). Effect of pectin on jejunal glucose absorption and unstirred layer thickness in normal man. Gut, 25, 936-941.

Jenkins, D.J.A., Wolever, T.M.S., Leeds, A.R., Gassull, M.A., Haisman, P., Dilawari, J., Goff, D.V., Mets, G.L. and Alberti, K.G.M.M.
(1978). Dietry fibres, fibre analogues, and glucose tolerance: Importance of viscosity. Br. Med. J., 1, 1392-1394.

Maki, Y., Sakata, T., Yamanaka, N. and Ogawa, N. (2001). Physicochemical properties of viscous exudate of "Mekabu" (part 3). Influences of preparation temperature on viscosity of viscous exudate of "Mekabu" (sporophyll of Undaria pinnatifida), and factors in changes in property. J. Cookery Sci. Jpn, (in press).

Oku, T. (1995). In "Dietary Fiber," ed. by S. Innami and S. Kiriyama, Daiichi Shuppan, Tokyo, pp.188-192.

Sakaguchi, E. and Nabata, A. (1992). Comparison of fibre digestion and digesta retention time between nutrias (Myocaster coypus) and guinea-pigs (Cavia porcellus). Comp. Biochem. Physiol., 103A, 601-604.

Takeda, T. and Kiriyama, S. (1995). In "Dietary Fiber," ed. by S. Innami and S. Kiriyama, Daiichi Shuppan, Tokyo, pp. 68-71.

Takehisa, F. (1997). In "Dietary Fiber," ed. by K. Tsuji and K. Doi, Asakura Shoten, Tokyo, pp. 69-71.

Thielemans, M.F., Francois, E., Bodart, C. and Thewis, A. (1978). Measure du transit gastrointestinal chez le proc a laide des rediolanthides. Comparaison avec le mouton. Annal. Biol. Anim. Biochem. Biophys., 18(2A), 237-247.

Yamanaka, N., Ogawa, N. and Sakata, T. (1996). Influences of sodium alginate extracted from "Mekabu" (sporophyll of Undaria pinnatifida) on digestive organs and cecal contents in rats. Food Sci. Technol., Int., 2, 108-112.

Yamanaka, N. and Ogawa, N. (1998). Physicochemical properties of viscous exudate of "Mekabu" (sporophyll of Undaria pinnatifida). Nippon Chouri Kagaku Kaishi, 31, 2-6 (in Japanese).

Yamanaka, N., Ogawa, N. and Sugawa-Katayama, Y. (1998). Effects of the viscous exudate of "Mekabu" (sporophyll of Undaria pinnatifida) on gastrointestinal tracts and plasma lipids in rats. Nippon Syokumotuseni Kenkyuukaisi, 1, 7-14 (in Japanese).

Yamanaka, N. and Ogawa, N. (1999). Factors influencing the physical property of viscous exudate of "Mekabu" and its digestibility. Presented at the 51st Congress of Nippon Kasei Gakkai, Nagoya, May 28-30, p.150 (in Japanese).

Yamanaka, N. and Ogawa, N. (2000). Physicochemical properties of viscous exudate of "Mekabu" (part 2). Influences of preparing condition on viscosity of viscous exudate of "Mekabu" (sporophyll of Undaria pinnatifida). Nippon Chouri Kagaku Kaishi, 33, 44-52 (in Japanese). 